Research Paper

\title{
Water Soluble Vitamins Enhance the Growth of Microorganisms in Peripheral Parenteral Nutrition Solutions
}

\author{
Sachiko Omotani ${ }^{1}$, Katsuji Tani ${ }^{2}$, Katsuhito Nagai ${ }^{1}$, Yasutoshi Hatsuda ${ }^{1}$, Junji Mukai ${ }^{1}$ and Michiaki \\ Myotoku1 ${ }^{\bowtie}$ \\ 1. Laboratory of Practical Pharmacy and Pharmaceutical Care, Faculty of Pharmacy, Osaka Ohtani University \\ 2. Laboratory of Environmental Science and Microbiology, Faculty of Pharmacy, Osaka Ohtani University. \\ $\bowtie$ Corresponding author: Michiaki Myotoku, 3-11-1, Nishikiori-kita, Tondabayashi-shi, Osaka 584-8540, Japan E-mail: myoutom@osaka-ohtani.ac.jp \\ (C) Ivyspring International Publisher. This is an open access article distributed under the terms of the Creative Commons Attribution (CC BY-NC) license \\ (https://creativecommons.org/licenses/by-nc/4.0/). See http://ivyspring.com/terms for full terms and conditions.
}

Received: 2017.06.12; Accepted: 2017.08.21; Published: 2017.09.19

\begin{abstract}
Peripheral parenteral nutrition (PPN) solutions contain amino acids, glucose, and electrolytes, with or without some water soluble vitamins. Peripheral venous catheters are one of the causes of catheter related blood stream infection (CRBSI), which requires infection control. In Japan, PPN solutions have rarely been prepared under aseptic conditions. However, in recent years, the necessity of adding vitamins to infusions has been reported. Therefore, we investigated the effects of water soluble vitamins on growth of microorganisms in PPN solutions. AMINOFLUID ${ }^{\circledR}(A F)$, BFLUID $^{\circledR}(B F)$, PARESAFE $^{\circledR}$ (PS) and PAREPLUS ${ }^{\circledR}(\mathrm{PP})$ PPN solutions were used. Water soluble vitamins contained in PP were also used. Causative microorganisms of CRBSI were used. Staphylococcus epidermidis decreased after 24 hours or 48 hours in all solutions. On the other hand, Escherichia coli, Serratia marcescens, Pseudomonas aeruginosa, Staphylococcus aureus and Candida albicans increased, especially in PP. When each water soluble vitamin was added to BF and PS, growth of $S$. aureus was greater in solutions that contained nicotinamide than in solutions that contained other vitamins. As for C. albicans, they grew in all test solutions. C. albicans grew especially well in solutions that contained biotin. When commercial amino acids and glucose solutions with electrolytes are administered, in particular those containing multivitamins or water soluble vitamins, efforts to control infection must be taken to prevent proliferation of microorganisms.
\end{abstract}

Key words: Peripheral parenteral nutrition; water soluble vitamin; catheter related blood stream infection; bacteria; fungi.

\section{Introduction}

One method for nutritional care is parenteral nutrition $(\mathrm{PN})$, which is classified into peripheral parenteral nutrition (PPN) and total parenteral nutrition (TPN). PPN is commonly used to maintain nutritional status for a short term in Japan.

Catheter related blood stream infection (CRBSI) is due to peripheral vein catheters and central venous catheters, which are common causes of healthcare associated infection. CRBSI results in a systemic infection. There are many studies on CRBSI [1-6]. Routes for contamination of catheters are recognized as follows: direct contamination of the catheter or catheter hub, contact with hands, contaminated fluids or devices, and rarely, infusate contamination may lead to CRBSI [7].

Preparation of infusion fluid should be done under aseptic conditions. In United States, all solutions are prepared aseptically [8]. However, in Japan, it is reported that $60.8 \%$ of hospitals have never prepared TPN solutions under aseptic conditions, and $76.5 \%$ of hospitals have never prepared PPN solutions under aseptic conditions [9]. Contamination of the 
environment has been reported as the cause of nosocomial infections [10-13]. It is clear that the environment of preparation for infusion fluids is highly associated with bacterial contamination in infusions.

Recently, there are reports that some water soluble vitamins should be added to PPN solutions in Japan [14-15]. However, it has been reported that some microorganisms can grow with multivitamin and lipid emulsion in PPN solutions [16].

Therefore, PPN solutions and water soluble vitamins, which are components of PPN solutions, were evaluated for their ability to support bacterial and fungal growth, which are the causes of CRBSI.

\section{Materials and Methods}

\section{Microorganisms employed}

The standard strain was used for each microorganism; Staphylococcus epidermidis JCM 2414,
Escherichia coli W3110, Serratia marcescens NBRC 3046, Pseudomonas aeruginosa PAO001, Staphylococcus aureus NBRC 12732 and NBRC 14462, and Candida albicans IFM 40009 and IFM 61197. C. albicans IFM 40009 and IFM 61197 were obtained from the National BioResource Project (http:/ /www. nbrp. jp/).

\section{Test solutions}

PPN solutions, which contain a commercial 3\% amino acid/ $7.5 \%$ glucose solution and electrolytes with or without water soluble vitamins, were used. They were AMINOFLUID ${ }^{\circledR}$ (AF; Otsuka Pharmaceutical Factory, Inc., Japan), BFLUID ${ }^{\circledR}$ (BF; Otsuka Pharmaceutical Factory, Inc., Japan), PARESAFE $^{\circledR}$ (PS; Yoshindo Inc., Japan) and PAREPLUS $^{\circledR}$ (PP; Yoshindo Inc., Japan). The compositions of AF, BF, PS and PP are shown in Table 1.

Table 1. The Compositions of AF, BF, PS and PP

\begin{tabular}{|c|c|c|c|c|c|}
\hline & Composition per $1000 \mathrm{~mL}$ & AMINOFLUID $^{\mathbb{R}}$ & BFLUID $^{\mathbb{R}}$ & PARESAFE $^{\mathbb{R}}$ & PAREPLUS $^{R}$ \\
\hline \multirow{22}{*}{ Amino Acids } & L-Leucine (g) & 4.2 & 4.2 & 4.2 & 4.2 \\
\hline & L-Isoleucine (g) & 2.4 & 2.4 & 2.4 & 2.4 \\
\hline & L-Valine $(\mathrm{g})$ & 2.4 & 2.4 & 2.4 & 2.4 \\
\hline & L-Lysine-Hydrochloride (g) & 3.93 & 3.93 & 3.93 & 3.93 \\
\hline & (as L-Lysine) & $(3.146)$ & (3.146) & $(3.146)$ & $(3.146)$ \\
\hline & L-Threonine (g) & 1.71 & 1.71 & 1.71 & 1.71 \\
\hline & L-Tryptophan (g) & 0.6 & 0.6 & 0.6 & 0.6 \\
\hline & L-Methionine (g) & 1.17 & 1.17 & 1.17 & 1.17 \\
\hline & Acetylcysteine (g) & & 0.404 & & 0.404 \\
\hline & (as L-Cysteine) & - & $(0.30)$ & - & $(0.30)$ \\
\hline & L-Cysteine (g) & 0.3 & - & 0.3 & - \\
\hline & L-Phenylalanine $(\mathrm{g})$ & 2.1 & 2.1 & 2.1 & 2.1 \\
\hline & L-Tyrosine (g) & 0.15 & 0.15 & 0.15 & 0.15 \\
\hline & L-Arginine $(g)$ & 3.15 & 3.15 & 3.15 & 3.15 \\
\hline & L-Histidine $(\mathrm{g})$ & 1.5 & 1.5 & 1.5 & 1.5 \\
\hline & L-Alanine $(\mathrm{g})$ & 2.4 & 2.4 & 2.4 & 2.4 \\
\hline & L-Proline (g) & 1.5 & 1.5 & 1.5 & 1.5 \\
\hline & $\mathrm{L}$-Serine $(\mathrm{g})$ & 0.9 & 0.9 & 0.9 & 0.9 \\
\hline & Glycine $(\mathrm{g})$ & 1.77 & 1.77 & 1.77 & 1.77 \\
\hline & L-Aspartic Acid (g) & 0.3 & 0.3 & 0.3 & 0.3 \\
\hline & L-Glutamic Acid (g) & 0.3 & 0.3 & 0.3 & 0.3 \\
\hline & Total Amino Acids (g) & 30 & 30 & 30 & 30 \\
\hline \multirow{13}{*}{$\begin{array}{l}\text { Electrolytic } \\
\text { Solution }\end{array}$} & $\mathrm{Na}^{+*}(\mathrm{mEq})$ & 35 & 35 & 34.2 & 34.2 \\
\hline & $\mathrm{K}^{+}(\mathrm{mEq})$ & 20 & 20 & 20 & 20 \\
\hline & $\mathrm{Mg}^{2+}(\mathrm{mEq})$ & 5 & 5 & 5 & 5.1 \\
\hline & $\mathrm{Ca}^{2+}(\mathrm{mEq})$ & 5 & 5 & 5 & 5 \\
\hline & $\mathrm{Cl}(\mathrm{mEq})$ & 35 & 35 & 35.2 & 35.2 \\
\hline & $\mathrm{SO}_{4}^{2}(\mathrm{mEq})$ & 5 & 5 & 5 & 5.1 \\
\hline & Acetate $^{*}(\mathrm{mEq})$ & 13 & 16 & 19 & 1.2 \\
\hline & Gluconate $(\mathrm{mEq})$ & 5 & - & 5 & - \\
\hline & L-Lactate $(\mathrm{mEq})$ & 20 & 20 & - & - \\
\hline & Lactate $(\mathrm{mEq})$ & - & - & 20 & 25.5 \\
\hline & Citrate $^{5 * *}(\mathrm{mEq})$ & 6 & 6 & - & 12 \\
\hline & $\mathrm{P}(\mathrm{mmol})$ & 10 & 10 & 10 & 10 \\
\hline & $\mathrm{Zn}(\mu \mathrm{mol})$ & 5 & 5 & 4.8 & 4.9 \\
\hline \multirow{12}{*}{ Vitamin } & Thiamine Chloride Hydrochloride (mg) & - & 1.92 & 2 & 3.81 \\
\hline & Riboflavin Sodium Phosphate (mg) & - & - & - & 2.5 \\
\hline & Pyridoxine Hydrochloride (mg) & - & - & - & 2.5 \\
\hline & Cyanocobalamin $(\mu \mathrm{g})$ & - & - & - & 5 \\
\hline & Ascorbic Acid (mg) & - & - & - & 100 \\
\hline & Folic Acid (mg) & - & - & - & 0.2 \\
\hline & Biotin ( $\mathrm{gg})$ & - & - & - & 50 \\
\hline & Nicotinamide $(\mathrm{mg})$ & - & - & - & 20 \\
\hline & Panthenol (mg) & - & - & - & 7.5 \\
\hline & Glucose $(\mathrm{g})$ & 75 & 75 & 74.998 & 74.998 \\
\hline & $\mathrm{pH}$ & Approximately 6.7 & Approximately 6.7 & Approximately 6.7 & Approximately 6.9 \\
\hline & OPR & Approximately 3 & Approximately 3 & Approximately 3 & Approximately 3 \\
\hline
\end{tabular}

*: including the amount derived from the additives. OPR: osmotic pressure ratio to physiological saline. 
The water soluble vitamins used were thiamine chloride hydrochloride $\left(\mathrm{VB}_{1}\right.$; Metabolin ${ }^{\circledR} \mathrm{-G}$ Injection 10 mg., Takeda Pharmaceutical Co., Ltd., Japan), riboflavin sodium phosphate $\left(\mathrm{VB}_{2}\right.$; Bisulase ${ }^{\circledR}$ inj. 10 mg, Toa Eiyo Ltd., Japan), pyridoxine hydrochloride $\left(V_{6}\right.$; Vitamin $B_{6}$ inj. "Nichi-Iko"10 mg, Nichi-Iko Pharmaceutical Co., Ltd., Japan), cyanocobalamin (VB 12 ; Cyanocobalamin Injection $1000 \mu \mathrm{g}$ "TOWA", Towa Pharmaceutical Co., Ltd., Japan), ascorbic acid (VC; Vitacimin ${ }^{\circledR}$ Injection 100 mg., Takeda Pharmaceutical Co., Ltd., Japan), nicotinic acid (Nicotinic Acid; Nyclin ${ }^{\circledR}$ inj.20 mg, Toa Eiyo Ltd., Japan), panthenol (Panthenol; Pantol ${ }^{\circledR}$ inj. $100 \mathrm{mg}$, Toa Eiyo Ltd., Japan), biotin (VH; Biotin Injection 1 mg "Fuso", Fuso Pharmaceutical Industries, Ltd., Japan) and folic acid (Folic Acid; Foliamin ${ }^{\circledR}$ Injection $15 \mathrm{mg}$, Nihon Pharmaceutical Co., Ltd., Japan).

In the experiment to observe the influence of each water soluble vitamin on microbial growth in PPN solutions, one ampoule of each water soluble vitamin was added to $500 \mathrm{~mL}$ of each PPN solution to prepare a test solution.

\section{Culture methods and sampling}

All bacteria were added to $5 \mathrm{~mL}$ of Luria-Bertani (LB) medium in sterile centrifuge tubes, and incubated at $37^{\circ} \mathrm{C}$ overnight. C. albicans was added to $10 \mathrm{~mL}$ of Sabouraud broth in a sterile centrifuge tube, and incubated at $37^{\circ} \mathrm{C}$. After 12 hours, they were transferred into $200 \mathrm{~mL}$ of fresh Sabouraud broth in sterile flasks, and incubated at $37^{\circ} \mathrm{C}$ overnight. Then, microbial cells were collected and washed with sterile phosphate-buffered saline (PBS) by centrifugation. A specified number of each test microorganism was added to $10 \mathrm{~mL}$ of each test solution in sterile centrifuge tubes, and the final microorganism concentration was adjusted from $10^{0}$ to $10^{3}$ colony-forming unit (CFU) / $\mathrm{mL}$. Each test solution aliquot sampled was kept at $25{ }^{\circ} \mathrm{C}$. They were sampled after 24 hours and 48 hours. These experiments were performed at least twice.

\section{Enumeration of viable cells}

When necessary, each test solution sampled was serially diluted ten-fold with phosphate buffer. Each test solution aliquot sample for bacteria was spread on standard agar (PEARLCORE NUTRIENT AGAR 'Eiken', Eiken Chemical Co., Ltd., Japan) plates in triple; fungi was spread on Sabouraud agar plates. After 24 to 48 hours of incubation at $37^{\circ} \mathrm{C}$, colonies formed on the plates were counted, and concentration was calculated. Similar with other experimental studies of microbial growth [16-18], the data obtained in this study were not analyzed statistically because biological significance of these kinds of data is considered assessable without statistical analysis.

\section{Results}

\section{Microbial growth in several PPN solutions}

Since the results of the experiments showed similar tendencies, one of them was indicated as the result. Microbial growth in PPN solutions is shown in Fig.1. S. epidermidis JCM2414 decreased after 24 hours or 48 hours in all solutions. It decreased to undetectable levels in some solutions. E. coli W3110 grew in all solutions. E. coli increased especially in PP, from $5.8 \times 10^{1} \mathrm{CFU} / \mathrm{mL}$ to $1.4 \times 10^{3} \mathrm{CFU} / \mathrm{mL} 24$ hours after, and to $1.1 \times 10^{5} \mathrm{CFU} / \mathrm{mL} 48$ hours after. $S$. marcescens NBRC 3046 also grew in all solutions, especially in PP. It increased from $7.4 \times 10^{1} \mathrm{CFU} / \mathrm{mL}$ to $3.2 \times 10^{5} \mathrm{CFU} / \mathrm{mL} 24$ hours after, and reached $7.3 \times 10^{8} \mathrm{CFU} / \mathrm{mL}$. P. aeruginosa PAO001 grew in all solutions, and especially in PP. It increased from $3.9 \times 10^{1} \mathrm{CFU} / \mathrm{mL}$ to $9.8 \times 10^{3} \mathrm{CFU} / \mathrm{mL} 24$ hours after, and reached $4.6 \times 10^{7} \mathrm{CFU} / \mathrm{mL} 48$ hours after. However, S. aureus NBRC 12732 grew in PP, but it hardly increased in BF and PS, and it decreased in AF. It grew in PP from $1.8 \times 10^{1} \mathrm{CFU} / \mathrm{mL}$ to $9.2 \times 10^{2} \mathrm{CFU} /$ $\mathrm{mL} 24$ hours after, and increased to $5.3 \times 10^{5} \mathrm{CFU} / \mathrm{mL}$ 48 hours after. On the other hand, S. aureus NBRC 14462 decreased by 1 or 2 orders of magnitude in all solutions.

The 2 strains of $C$. albicans grew in all solutions. Both strains grew especially in PP. C. albicans IFM 40009 increased from $1.8 \times 10^{2} \mathrm{CFU} / \mathrm{mL}$ to $1.8 \times 10^{5}$ CFU / mL 24 hours after, and reached $1.1 \times 10^{7} \mathrm{CFU} /$ $\mathrm{mL} 48$ hours after. C. albicans IFM 61197 increased from $7.5 \times 10^{1} \mathrm{CFU} / \mathrm{mL}$ to $3.5 \times 10^{4} \mathrm{CFU} / \mathrm{mL} 24$ hours after, and reached $1.6 \times 10^{7} \mathrm{CFU} / \mathrm{mL} 48$ hours after. Both strains of $C$. albicans moderately grew in $\mathrm{AF}, \mathrm{BF}$ and PS.

\section{Microbial growth in PPN solutions containing each water soluble vitamin}

Since the results of the experiments showed similar tendencies, one of them was indicated as the result. Microbial growth in PPN solutions containing each water soluble vitamin is shown in Table 2 . When each water soluble vitamin was added to $\mathrm{AF}, \mathrm{S}$. aureus NBRC 12732 was hardly detected in all solutions. On the other hand, when each water soluble vitamin was added to BF and PS, S. aureus NBRC 12732 increased in all solutions after 24 hours or 48 hours. In particular, S. aureus in the solutions with nicotinamide increased by more than 2 orders of magnitude. It increased from $1.8 \times 10^{1} \mathrm{CFU} / \mathrm{mL}$ to $9.4 \times 10^{3} \mathrm{CFU} /$ $\mathrm{mL} 48$ hours after in $\mathrm{BF}$, and from $5.0 \times 10^{\circ} \mathrm{CFU} / \mathrm{mL}$ to $5.0 \times 10^{3} \mathrm{CFU} / \mathrm{mL} 48$ hours after in PS. 
Staphylococcus epidermidis JCM 2414

$\mathrm{CFU} / \mathrm{mL}$

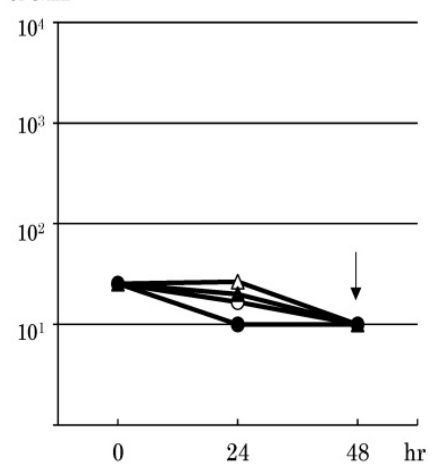

Serratia marcescens NBRC 3046 $\mathrm{CFU} / \mathrm{mL}$

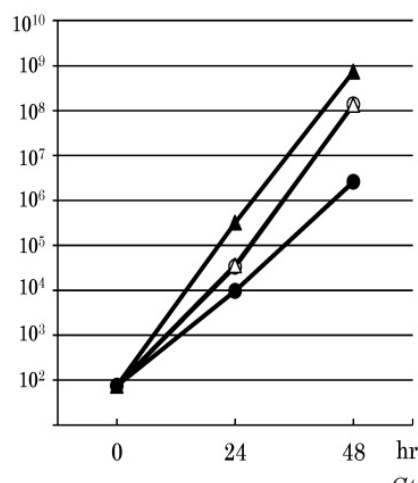

NBRC 12732

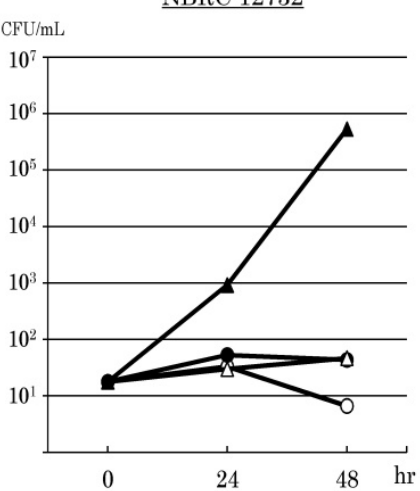

Escherichia coli W3110

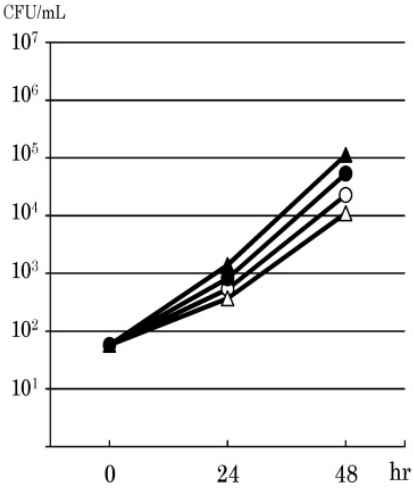

Pseudomonas aeruginosa PAO001

$\mathrm{CFU} / \mathrm{mL}$

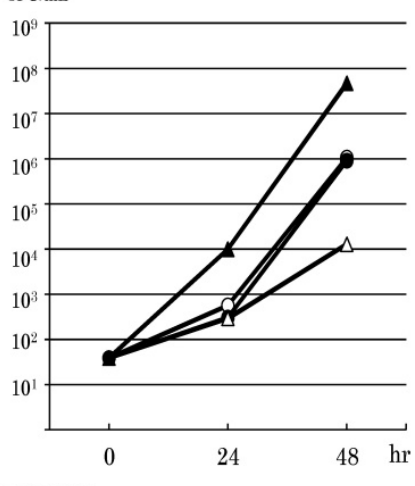

NBRC 14462

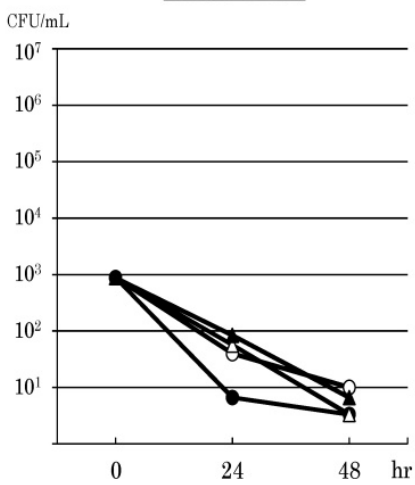

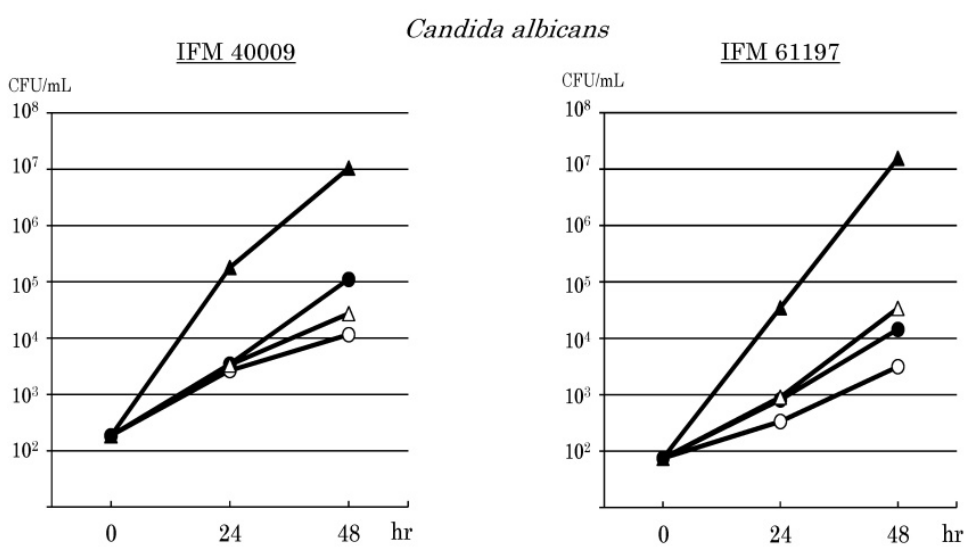

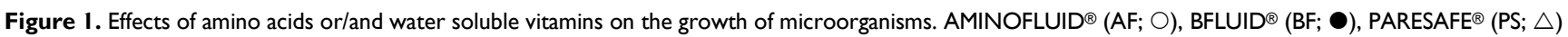
and PAREPLUS ${ }^{\circledR}$ (PP; $\left.\mathbf{\Delta}\right)$ were used. BF and PS contain only VB।; PP contains multivitamins. The down arrow indicates undetectable levels. 
Table 2. Growth of Staphylococcus aureus and Candida albicans in PPN solutions containing each water soluble vitamin (CFU/mL)

\begin{tabular}{|c|c|c|c|c|c|c|c|c|c|c|}
\hline & & \multicolumn{3}{|c|}{ AMINOFLUID $^{8}$ (CFU/mL) } & \multicolumn{3}{|c|}{ BFLUID $^{\sqrt{8}}$ (CFU/mL) } & \multicolumn{3}{|c|}{ PARESAFE $^{8 /}(\mathrm{CFU} / \mathrm{mL})$} \\
\hline & & $0 \mathrm{hr}$ & $24 \mathrm{hr}$ & $48 \mathrm{hr}$ & $0 \mathrm{hr}$ & $24 \mathrm{hr}$ & $48 \mathrm{hr}$ & $0 \mathrm{hr}$ & $24 \mathrm{hr}$ & $48 \mathrm{hr}$ \\
\hline \multirow{9}{*}{$\begin{array}{c}\text { Staphylococcus aureus } \\
\text { NBRC } 12732\end{array}$} & $\mathrm{VB}_{1}$ & $7.8 \times 10^{0}$ & $3.3 \times 10^{1}$ & ND & - & - & - & - & - & - \\
\hline & $\mathrm{VB}_{2}$ & $7.8 \times 10^{0}$ & $1.7 \times 10^{1}$ & $1.00 \times 10^{1}$ & $1.8 \times 10^{1}$ & $1.2 \times 10^{2}$ & $7.7 \times 10^{1}$ & $5.0 \times 10^{0}$ & $4.3 \times 10^{1}$ & $4.0 \times 10^{1}$ \\
\hline & $\mathrm{VB}_{6}$ & $7.8 \times 10^{0}$ & ND & ND & $1.8 \times 10^{1}$ & $6.0 \times 10^{1}$ & $6.3 \times 10^{1}$ & $5.0 \times 10^{0}$ & $1.0 \times 10^{1}$ & $1.0 \times 10^{1}$ \\
\hline & $\mathrm{VB}_{12}$ & $7.8 \times 10^{0}$ & ND & ND & $1.8 \times 10^{1}$ & $8.0 \times 10^{1}$ & $2.3 \times 10^{1}$ & $5.0 \times 10^{0}$ & $1.7 \times 10^{1}$ & $1.7 \times 10^{1}$ \\
\hline & $\mathrm{VC}$ & $7.8 \times 10^{0}$ & ND & ND & $1.8 \times 10^{1}$ & $9.7 \times 10^{1}$ & $8.3 \times 10^{1}$ & $5.0 \times 10^{0}$ & $3.3 \times 10^{0}$ & $2.3 \times 10^{1}$ \\
\hline & Nicotinamide & $7.8 \times 10^{0}$ & $1.0 \times 10^{1}$ & ND & $1.8 \times 10^{1}$ & $2.9 \times 10^{2}$ & $9.4 \times 10^{3}$ & $5.0 \times 10^{0}$ & $1.5 \times 10^{2}$ & $5.0 \times 10^{3}$ \\
\hline & Panthenol & $7.8 \times 10^{0}$ & $1.7 \times 10^{1}$ & ND & $1.8 \times 10^{1}$ & $7.0 \times 10^{1}$ & $3.3 \times 10^{1}$ & $5.0 \times 10^{0}$ & $2.0 \times 10^{1}$ & $1.3 \times 10^{1}$ \\
\hline & Biotin & $7.8 \times 10^{0}$ & $1.0 \times 10^{1}$ & ND & $1.8 \times 10^{1}$ & $4.7 \times 10^{1}$ & $3.0 \times 10^{1}$ & $5.0 \times 10^{0}$ & $1.0 \times 10^{1}$ & $6.7 \times 10^{0}$ \\
\hline & Folic Acid & $7.8 \times 10^{0}$ & ND & ND & $1.8 \times 10^{1}$ & $5.0 \times 10^{1}$ & $2.7 \times 10^{1}$ & $5.0 \times 10^{0}$ & $3.0 \times 10^{1}$ & $1.0 \times 10^{1}$ \\
\hline \multirow{11}{*}{$\begin{array}{l}\text { Candida albicans } \\
\text { IFM } 40009\end{array}$} & & \multicolumn{3}{|c|}{ AMINOFLUID ${ }^{i \hbar}(\mathrm{CFU} / \mathrm{mL})$} & \multicolumn{3}{|c|}{ BFLUID $^{\text {i }}(\mathrm{CFU} / \mathrm{mL})$} & \multicolumn{3}{|c|}{ PARESAFE ${ }^{\circ}(\mathrm{CFU} / \mathrm{mL})$} \\
\hline & & $0 \mathrm{hr}$ & $24 \mathrm{hr}$ & $48 \mathrm{hr}$ & $0 \mathrm{hr}$ & $24 \mathrm{hr}$ & $48 \mathrm{hr}$ & $0 \mathrm{hr}$ & $24 \mathrm{hr}$ & $48 \mathrm{hr}$ \\
\hline & $\mathrm{VB}_{1}$ & $5.7 \times 10^{0}$ & $2.1 \times 10^{2}$ & $7.7 \times 10^{3}$ & - & - & - & - & - & - \\
\hline & $\mathrm{VB}_{2}$ & $5.7 \times 10^{0}$ & $2.4 \times 10^{2}$ & $1.1 \times 10^{3}$ & $1.8 \times 10^{2}$ & $1.0 \times 10^{4}$ & $5.2 \times 10^{5}$ & $4.8 \times 10^{0}$ & $7.0 \times 10^{1}$ & $6.8 \times 10^{2}$ \\
\hline & $\mathrm{VB}_{6}$ & $5.7 \times 10^{0}$ & $9.0 \times 10^{1}$ & $1.9 \times 10^{3}$ & $1.8 \times 10^{2}$ & $1.8 \times 10^{3}$ & $2.3 \times 10^{5}$ & $4.8 \times 10^{0}$ & $8.0 \times 10^{1}$ & $6.2 \times 10^{2}$ \\
\hline & $\mathrm{VB}_{12}$ & $5.7 \times 10^{0}$ & $8.0 \times 10^{1}$ & $1.5 \times 10^{3}$ & $1.8 \times 10^{2}$ & $5.6 \times 10^{3}$ & $3.0 \times 10^{5}$ & $4.8 \times 10^{0}$ & $8.0 \times 10^{1}$ & $6.9 \times 10^{2}$ \\
\hline & $\mathrm{VC}$ & $5.7 \times 10^{0}$ & $1.3 \times 10^{2}$ & $3.1 \times 10^{3}$ & $1.8 \times 10^{2}$ & $1.5 \times 10^{4}$ & $1.5 \times 10^{6}$ & $4.8 \times 10^{0}$ & $7.0 \times 10^{1}$ & $2.3 \times 10^{3}$ \\
\hline & Nicotinamide & $5.7 \times 10^{0}$ & $7.3 \times 10^{1}$ & $3.4 \times 10^{3}$ & $1.8 \times 10^{2}$ & $4.5 \times 10^{3}$ & $3.2 \times 10^{5}$ & $4.8 \times 10^{0}$ & $1.1 \times 10^{2}$ & $3.6 \times 10^{2}$ \\
\hline & Panthenol & $5.7 \times 10^{0}$ & $1.1 \times 10^{2}$ & $3.4 \times 10^{3}$ & $1.8 \times 10^{2}$ & $5.0 \times 10^{3}$ & $2.5 \times 10^{5}$ & $4.8 \times 10^{0}$ & $1.7 \times 10^{2}$ & $3.6 \times 10^{2}$ \\
\hline & Biotin & $5.7 \times 10^{0}$ & $5.2 \times 10^{2}$ & $3.7 \times 10^{5}$ & $1.8 \times 10^{2}$ & $1.2 \times 10^{5}$ & $1.6 \times 10^{7}$ & $4.8 \times 10^{0}$ & $7.3 \times 10^{2}$ & $4.5 \times 10^{6}$ \\
\hline & Folic Acid & $5.7 \times 10^{0}$ & $1.7 \times 10^{2}$ & $2.8 \times 10^{3}$ & $1.8 \times 10^{2}$ & $5.5 \times 10^{3}$ & $3.0 \times 10^{5}$ & $4.8 \times 10^{0}$ & $6.3 \times 10^{1}$ & $5.4 \times 10^{2}$ \\
\hline \multirow{11}{*}{$\begin{array}{l}\text { Candida albicans } \\
\text { IFM } 61197\end{array}$} & & \multicolumn{3}{|c|}{ AMINOFLUID $^{\sigma 0}(\mathrm{CFU} / \mathrm{mL})$} & \multicolumn{3}{|c|}{ BFLUID $^{\sqrt{8}}(\mathrm{CFU} / \mathrm{mL})$} & \multicolumn{3}{|c|}{ PARESAFE $^{8 \%}(\mathrm{CFU} / \mathrm{mL})$} \\
\hline & & $0 \mathrm{hr}$ & $24 \mathrm{hr}$ & $48 \mathrm{hr}$ & $0 \mathrm{hr}$ & $24 \mathrm{hr}$ & $48 \mathrm{hr}$ & $0 \mathrm{hr}$ & $24 \mathrm{hr}$ & $48 \mathrm{hr}$ \\
\hline & $\mathrm{VB}_{1}$ & $7.5 \times 10^{1}$ & $3.6 \times 10^{2}$ & $4.5 \times 10^{3}$ & - & - & - & - & - & - \\
\hline & $\mathrm{VB}_{2}$ & $7.5 \times 10^{1}$ & $7.1 \times 10^{2}$ & $1.2 \times 10^{4}$ & $2.1 \times 10^{2}$ & $1.9 \times 10^{3}$ & $1.2 \times 10^{6}$ & $1.1 \times 10^{2}$ & $5.1 \times 10^{2}$ & $2.1 \times 10^{4}$ \\
\hline & $\mathrm{VB}_{6}$ & $7.5 \times 10^{1}$ & $2.8 \times 10^{2}$ & $3.4 \times 10^{3}$ & $2.1 \times 10^{2}$ & $1.1 \times 10^{3}$ & $3.1 \times 10^{5}$ & $1.1 \times 10^{2}$ & $5.7 \times 10^{2}$ & $1.2 \times 10^{4}$ \\
\hline & $\mathrm{VB}_{12}$ & $7.5 \times 10^{1}$ & $4.2 \times 10^{2}$ & $4.1 \times 10^{3}$ & $2.1 \times 10^{2}$ & $1.6 \times 10^{3}$ & $6.1 \times 10^{5}$ & $1.1 \times 10^{2}$ & $3.9 \times 10^{2}$ & $1.5 \times 10^{4}$ \\
\hline & $\mathrm{VC}$ & $7.5 \times 10^{1}$ & $7.6 \times 10^{2}$ & $1.1 \times 10^{4}$ & $2.1 \times 10^{2}$ & $5.9 \times 10^{3}$ & $2.3 \times 10^{6}$ & $1.1 \times 10^{2}$ & $9.6 \times 10^{2}$ & $1.4 \times 10^{5}$ \\
\hline & Nicotinamide & $7.5 \times 10^{1}$ & $5.0 \times 10^{2}$ & $4.6 \times 10^{3}$ & $2.1 \times 10^{2}$ & $1.5 \times 10^{3}$ & $4.9 \times 10^{5}$ & $1.1 \times 10^{2}$ & $3.2 \times 10^{2}$ & $1.2 \times 10^{4}$ \\
\hline & Panthenol & $7.5 \times 10^{1}$ & $4.2 \times 10^{2}$ & $3.1 \times 10^{3}$ & $2.1 \times 10^{2}$ & $8.7 \times 10^{2}$ & $2.0 \times 10^{5}$ & $1.1 \times 10^{2}$ & $4.0 \times 10^{2}$ & $1.5 \times 10^{4}$ \\
\hline & Biotin & $7.5 \times 10^{1}$ & $2.9 \times 10^{4}$ & $1.2 \times 10^{6}$ & $2.1 \times 10^{2}$ & $2.3 \times 10^{4}$ & $1.2 \times 10^{7}$ & $1.1 \times 10^{2}$ & $1.2 \times 10^{4}$ & $7.7 \times 10^{6}$ \\
\hline & Folic Acid & $7.5 \times 10^{1}$ & $4.3 \times 10^{2}$ & $3.9 \times 10^{3}$ & $2.1 \times 10^{2}$ & $1.0 \times 10^{3}$ & $3.3 \times 10^{5}$ & $1.1 \times 10^{2}$ & $3.0 \times 10^{2}$ & $1.2 \times 10^{4}$ \\
\hline
\end{tabular}

ND: not detected

When each water soluble vitamin was added to $\mathrm{AF}, \mathrm{BF}$ and PS, the 2 strains of $C$. albicans increased in all solutions, especially in solutions with biotin.

\section{Discussion}

Many pathogenic bacteria require glucide, fatty acids and amino acids as carbon compounds [19]. C. albicans, which is a fungus, can grow with amino acids, glucide and hydrocarbons [20]. TPN solutions contain amino acids, glucose, electrolytes, and are with or without lipid emulsion and multivitamins. TPN solutions are considered to be relatively good growth mediums for microorganisms due to the included components [21, 22].

In Japan, although hospitals that prepare TPN solutions under aseptic conditions are increasing, few prepare PPN solutions aseptically. PPN solutions, which have a lower nutritional value than TPN solutions, contain amino acids, glucose and electrolytes with or without water soluble vitamins.
Shiraishi et al. reported that bacterial growth depended on the nature of the bacterial species, as well as composition, $\mathrm{pH}$ and osmotic pressure [23]. In general, the optimum $\mathrm{pH}$ of bacterial growth is from 5.0 to 8.0, the optimum $\mathrm{pH}$ of pathogenic bacterial growth is from 7.2 to 7.6 and the osmotic pressure ratio to physiological saline (OPR) is $1.0[19,23]$. Fungi grow well near neutral $\mathrm{pH}$, but almost all fungi can grow even in a low $\mathrm{pH}$ [20]. The $\mathrm{pH}$ value of commercial PPN solutions, which are designed to be approximately 7 , is higher than that of commercial TPN solutions. The OPR of commercial PPN solutions, which is designed to be approximately 3 , is lower than that of commercial TPN solutions. Kuwahara et al. reported that bacteria could be grown by raising the $\mathrm{pH}$ in TPN solutions [24]. It has been reported that fungi can also grow in TPN solutions with a low $\mathrm{pH}$ [24]. Therefore, we consider that bacteria tend to grow better in PPN solutions than in TPN solutions. 
In the present study, we investigated the possibility of growth of microorganisms, such as $S$. epidermidis, E. coli, S. marcescens, $P$. aeruginosa, S. aureus and C. albicans, in PPN solutions. In particular, the addition of water soluble vitamins to PPN solutions was evaluated for its ability to support bacterial and fungal growth, which is a cause of CRBSI.

E. coli, S. marcescens and P. aeruginosa grew in all test solutions. E. coli is a eutrophic bacteria and inhabits the intestinal environment. $S$. marcescens and $P$. aeruginosa are oligotrophs. E. coli increased only by 3 to 4 orders of magnitude in each PPN solution. At the same time, $S$. marcescens increased by 5 to 7 orders of magnitude, and P. aeruginosa increased by up to 6 orders of magnitude in each PPN solution. Thus, growth of $S$. marcescens and $P$. aeruginosa was greater than that of $E$. coli. These results demonstrate that $S$. marcescens and $P$. aeruginosa can grow well in PPN solutions containing amino acids, glucose and electrolytes, which have lower nutrition than TPN solutions, and E. coli can grow mildly. In addition, these bacteria increased rapidly in $\mathrm{PP}$, which contains several water soluble vitamins. S. aureus NBRC 12732 hardly increased in AF, BF, and PS, but increased in PP by 4 orders of magnitude. S. aureus NBRC 14462 did not increase in all PPN solutions, but was decreased instead. As the auxotrophy of $S$. aureus is different, the growth of the 2 strains is different. The 2 strains of $C$. albicans grew in all PPN solutions, especially in PP. C. albicans increased by 2 to 3 orders of magnitude in test solutions other than PP, but increased by 5 to 6 orders of magnitude in PP. Kuwahara et al. reported the following: both B. cereus and $S$. marcescens increased rapidly in AF, $S$. aureus cannot grow in AF without lipid emulsion and multivitamins, but can grow rapidly with multivitamins. C. albicans increased slightly in AF without lipid emulsion and multivitamins, and the addition of lipid emulsion or multivitamins accelerated its growth [16]. These results suggest that the growth of microorganisms is due to differences in PPN solutions, and water soluble vitamins enhance their growth. Water soluble vitamins are considered to elevate the risk of infection.

Thus, addition of each water soluble vitamin to PPN solutions was evaluated for the ability to support $S$. aureus and $C$. albicans growth. In addition, since these microorganisms are important as causative microbial of CRBSI, three microorganisms were selected for the experiment. As a result of adding each water soluble vitamin contained in PP to each PPN solution, S. aureus NBRC 12732 hardly increased in $\mathrm{AF}$, which did not contain $\mathrm{VB}_{1}$, but increased in the test solutions made by mixing BF or PS with nicotinic acid. S. aureus in BF or PS with nicotinic acid increased by more than 2 orders of magnitude compared with in other test solutions. These results indicated that the addition of nicotinic acid among the water soluble vitamins to PPN solutions with $\mathrm{VB}_{1}$ enhanced the ability of these solutions to support growth of $S$. aureus. The 2 strains of $C$. albicans increased in all the test solutions, especially in the test solutions made by mixing $\mathrm{AF}, \mathrm{BF}$ or $\mathrm{PS}$ with biotin. C. albicans in test solutions with biotin increased by 2 to 4 orders of magnitude compared with in other test solutions. These results indicate that the addition of biotin to PPN solutions with or without $\mathrm{VB}_{1}$ enhances the ability of these solutions to support growth of $C$. albicans. Other than needing organic compounds for energy, fungi are often able to proliferate only with inorganic salts [20]. If they cannot grow in the sole carbon source, they often require a few vitamins in addition to inorganic salts [20]. Fungi frequently require biotin and thiamine [20]. Miyashita reported that biotin and thiamine were required growth promoting factors for C. albicans [25]. In the present study, as $C$. albicans could grow even in the test solution with biotin added to AF not containing $\mathrm{VB}_{1}$, we considered biotin to promote the growth of $C$. albicans.

It was suggested that PPN solutions support the growth of oligotrophs. Furthermore, we suggest that water soluble vitamins enhance the ability of PPN solutions to support growth of microorganisms. These results demonstrate that the addition of water soluble vitamins to PPN solutions increases the risk of infection.

\section{Conclusion}

In the Guidelines for Compounding Sterile Preparations [26], it has been described that preparation of infusion fluid for TPN solutions and peripheral amino acids must be prepared using aseptic manipulation in a class 100 (Federal Standard 209 D) environment. These results suggest the following: if the infusion was contaminated due to neglect of infection control at the time of preparing the infusion fluid for PPN solutions, microorganisms may grow in the infusion and cause infection. Microorganism species used in this study are reported as causes of CRBSI. As one method of infection control, it is necessary to prepare TPN solutions and PPN solutions for infusions under aseptic conditions.

Collectively, when commercial amino acids, glucose solutions and electrolytes with or without water soluble vitamins are administered, especially when multivitamins are contained or some water soluble vitamins are added, we must make an effort to control infection to prevent growth of microorganisms. 


\section{Competing Interests}

The authors have declared that no competing interest exists.

\section{References}

1. Aso Y, Nagatomi M, Nakazawa T, Sasaki S, Ishi K. Examination of infusion fluid type and environmental factors involved in increased Bacillus cereus bloodstream infection. Jpn J Infect Prev Control. 2012; 27:81-90.

2. Sato A, Nakamura I, Fukushima S, Mizuno Y, Matsumoto T. Peripheral line-associated blood stream infection. Jpn J Infect Prev Control. 2015; 30:1-6.

3. Pronovost P, Needham D, Berenholtz S, Sinopoli D, Chu H, Cosgrove S, et al. An intervention to decrease catheter-related bloodstream infections in the ICU. N Engl J Med. 2006; 355:2725-2732.

4. Schulman J, Stricof R, Stevens TP, Horgan M, Gase K, Holzman IR, et al. Statewide NICU central-line-associated bloodstream infection rates decline after bundles and checklists. Pediatrics. 2011; 127:436-444.

5. Mermel LA. Prevention of intravascular catheter-related infections. Ann Intern Med. 2000; 132:391-402.

6. Matsumoto S, Suenaga H, Naito K, Sawazaki M, Hiramatsu T, Agata N. Management of suspected nosocomial infection: an audit of 19 hospitalized patients with septicemia caused by Bacillus species. Jpn J Infect Dis. 2000; 53:196-202.

7. O'Grady NP, Alexander M, Burns LA, Dellinger EP, Garland J, Heard SO, et al. Guidelines for the prevention of intravascular catheter-related infections. Am J Infect Control. 2011; 39:S1-34.

8. American Society of Health System Pharmacists. ASHP guidelines on compounding sterile preparations. Am J Health Syst Pharm.2014; 71:145-166.

9. The Japanese Society of Hospital Pharmacists. Current situation survey of pharmaceutical department in 2015. J Jpn Soc Hosp Pharm. 2016; 52:761-832.

10. Hughes CF, Grant AF, Leckie BD, Baird DK. Cardioplegic solution: a contamination crisis. J Thorac Cardiovasc Surg. 1986; 91:296-302.

11. Anon. ASHP gears up multistep action plan regarding sterile drug products. Am J Hosp Pharm. 1991; 48:386,389-390.

12. Dugleux G, Le Coutour X, Hecquard C, Oblin I. Septicemia caused by contaminated parenteral nutrition pouches: the refrigerator as an unusual cause. J Parenter Enteral Nutr. 1991; 15:474-475.

13. Solomon SL, Khabbaz RF, Parker RH, Anderson RL, Geraghty MA, Furman $\mathrm{RM}$, et al. An outbreak of Candida parapsilosis bloodstream infections in patients receiving parenteral nutrition. J Infect Dis. 1984; 149:98-102.

14. Ozasa H, Ishibashi N, Ikeda S, Imaizumi T, Miyagi M, Yano S, et al. Clinical examination of the water-soluble vitamin levels in blood during peripheral parenteral nutrition. Kurume Med J. 2006; 53:79-87.

15. Fujiyama J, Kinomoto $\mathrm{K}$, Yamamura O, Fujii A, Ikawa M, Okuda $\mathrm{T}$, et al. Water-soluble vitamin levels in the fasting patients during peripheral parenteral nutrition without addition of vitamins. J Jpn Soc Parenter Enteral Nutr. 2007; 22:181-187.

16. Kuwahara T, Kaneda S, Shimono K, Inoue Y. Effects of lipid emulsion and multivitamins on the growth of microorganisms in peripheral parenteral nutrition solutions. Int J Med Sci. 2013; 10:1079-1084.

17. Obayashi A, Oie S, Kamiya A. Microbial viability in preparations packaged for single use. Biol Pharm Bull. 2003; 26:667-670.

18. Sakai Y, Konishi T, Obayashi Y, Honda K, Akae S, Ishihara K, et al. Study of growth level of Bacillus cereus in various infusion fluids. Shimane J Med Tech. 2012; 40:19-23.

19. Yoshida S, Yanagi Y, Yoshikai Y. Toda's new bacteriology 33rd edition. Tokyo, APAN: Nanzando; 2007:21-226.

20. Yoshida S, Yanagi Y, Yoshikai Y. Toda's new bacteriology 33rd edition. Tokyo, JAPAN: Nanzando; 2007:293-315

21. Allwood MC. Microbiological risks in parenteral nutrition compounding. Nutrition. 1997; 13:60-61.

22. Banton J. Techniques to prevent central venous catheter infections: products, research, and recommendations. Nutr Clin Pract. 2006; 21: 56-61.

23. Shiraishi T, Nakagawa Y. Evaluation of infusion fluids on outgrowth of several bacteria strains related to hospital-acquired infection. Jpn J Infect Prev Control. 2007; 22:165-169.

24. Kuwahara T, Kaneda S, Shimono K, Inoue Y. Growth of microorganisms in total parenteral nutrition solutions without lipid. Int J Med Sci. 2010; 7:43-47.

25. Miyashita S. Studies on the nutrition of Candida:1. Nutritional requirements of Candida. Jpn J Bacteriol. 1956; 11:907-910.

26. The Japanese Society of Hospital Pharmacists. Guidelines for compounding sterile preparations. Tokyo, JAPAN: Yakuji Nippo; 2008. 